\title{
CONTEXTUALIZAÇÃO NOS CURRÍCULOS DA ÁREA DE CIÊNCIAS DA NATUREZA E SUAS TECNOLOGIAS
}

\author{
Fabiane Andrade Leite ${ }^{1}$ \\ Judite Scherer Wenzel ${ }^{2}$ \\ Franciele Siqueira Radetzke ${ }^{3}$
}

\begin{abstract}
RESUMO
Este artigo apresenta como tema a contextualização nos processos de ensino da área de Ciências da Natureza e suas Tecnologias. O estudo busca identificar compreensões de contextualização descritas nas publicações do Encontro Nacional de Pesquisa em Educação em Ciências nos últimos dez anos e em documentos oficiais que norteiam o currículo da Educação Básica no Brasil. Por meio do processo de análise, foram identificadas três categorias: a) contextualização como ensino significativo; b) contextualização como inter-relação do conhecimento científico e do conhecimento cotidiano e c) contextualização como superação do modelo de ensino transmissivo. As categorias não são excludentes no processo de ensino e retratam novas compreensões de ensinar e de aprender, indicando a contextualização como modo de qualificar o ensino de ciências.
\end{abstract}

Palavras-chave: Contextualização. Ensino de Ciências. Significação conceitual.

\section{CONTEXTUALIZATION IN THE CURRICULUMS OF THE AREA OF NATURAL SCIENCES AND THEIR TECNOLOGIES}

\section{ABSTRACT}

This article presents how focus the contextualization in the teaching processes of the area of Natural Sciences and its Technologies. The study consists of identify comprehensions of contextualization described in the publications of the National Meeting of Research in Science Education in the last 10 years and in official documents that guide the curriculum of basic education in Brazil. Through the the process of analysis, three categories were identified: a) contextualization as meaningful teaching; b) contextualization as an interrelationship of scientific knowledge and everyday knowledge; and c) contextualization as an overcoming of the transmissive teaching model. The categories are not exclusive in the teaching process and portray new understandings of teaching and learning, indicating contextualization as a way of qualifying science teaching.

Keywords: Contextualization. Science teaching. Conceptual meaning.

\section{RECEBIDO EM: 9/7/2017}

REVISÕES REQUERIDAS EM: 5/11/2017

ACEITO EM: 22/5/2018

\footnotetext{
${ }^{1}$ Professora de Práticas de Ensino e Estágio Supervisionado na Universidade Federal da Fronteira Sul - UFFS, Campus Cerro Largo/RS. Doutora em Educação nas Ciências pela Unijuí/RS e mestre em Ensino Científico e Tecnológico pela URI/RS. Vinculada ao Grupo de Pesquisa em Ensino de Ciências e Matemática - Gepeciem da UFFS/RS. Realiza estudos e pesquisas na área da educação, principalmente nos seguintes temas: formação inicial e continuada de professores, metodologias de ensino, currículo escolar, aprendizagem em Química, história da ciência e epistemologia. http://buscatextual.cnpq.br/buscatextual/visualizacv.do?id=K4323636U2. http://orcid.org/0000-0002-4967-233X. fabiane.leite@uffs.edu.br

2 Professora e coordenadora do curso de Química - Licenciatura na Universidade Federal da Fronteira Sul - UFFS, Campus Cerro Largo/ RS. Doutora e mestre em Educação nas Ciências pela Unijuí/RS. Licenciada pela Universidade Federal de Santa Maria (UFSM). Vinculada ao Grupo de Pesquisa em Ensino de Ciências em Matemática - Gepeciem da UFFS/RS. Realiza estudos e pesquisas na área da educação, principalmente nos seguintes temas: formação inicial e continuada de professores, linguagem química, apropriação e significação conceitual numa perspectiva histórico-cultural, ensino e aprendizagem em Química. http://lattes.cnpq.br/1046786613009478. https:// orcid.org/0000-0002-6601-2990. juditescherer@uffs.edu.br

${ }^{3}$ Professora de Ciências da Educação Básica, Mestranda do Programa de Pós-Graduação em Ensino de Ciências PPGEC na Universidade Federal da Fronteira Sul - Campus Cerro Largo/RS. Tem atuado em projetos de pesquisa com foco nos processos de (re)contextualização do conhecimento e nas relações conceituais na área de Ciências da Natureza (Biologia, Física e Química). http://lattes.cnpq. br/6007927453058608. https://orcid.org/0000-0002-3222-7977. francielesradetzke@gmail.com
} 
Neste trabalho apresentamos compreensões acerca da contextualização na área de Ciências da Natureza e suas Tecnologias. A investigação é pertinente ao contexto atual da educação brasileira, tendo em vista que ao longo dos últimos 20 anos a temática da contextualização tem perpassado os processos de reestruturação curricular na Educação Básica. Com isso, tem sido foco das discussões que buscam a qualificação dos processos de ensino e aprendizagem, acentuando-se no contexto de elaboração da Base Nacional Comum Curricular (BNCC), que compreende o ensino como "um processo contínuo de contextualização histórica, social e cultural" (BRASIL, 2016 , p. 137). As discussões latentes, que decorrem da instituição da Base Nacional Comum Curricular, iniciadas no ano de 2015 , demarcam a importância de colocarmos em pauta a temática proposta.

Na BNCC a contextualização é apresentada como o processo de compreensão e intervenção dos alunos para o meio em que vivem, influenciando nas transformações de uma dada realidade (BRASIL, 2016).

No contexto educacional brasileiro a contextualização tem sido discutida ao longo dos últimos 20 anos por professores e pesquisadores da área de ensino, autores de livros didáticos e demais profissionais envolvidos com o processo de (re)construção do currículo na educação básica (LUTFI, 1992; VIGOTSKI, 2000, 2007; SILVA, 2007 ; ZANON, 2007; RADETZKE; LEITE; WENZEL, 2016 ). Cabe destacar que o termo contextualização decorre da reforma para o Ensino Médio, realizada a partir da Lei de Diretrizes e Bases da Educação Nacional (LDB n 9.394/96). Por meio da LDB, a perspectiva de currículo na Educação Básica foi redefinida, o que desencadeou a elaboração de parâmetros e diretrizes curriculares nacionais para o Ensino Médio. Os Parâmetros Curriculares Nacionais para o Ensino Médio (BRASIL, 2000) e as Diretrizes Curriculares Nacionais para a Educação Básica (BRASIL, 2010) foram estruturados sobre dois eixos principais: a interdisciplinaridade e a contextualização, com o objetivo de promover uma aprendizagem focada na formação do cidadão.

A presença do termo nos documentos oficiais, contudo, não garantiu a realização de processos metodológicos sob os princípios da contextualização e a interdisciplinaridade na educação básica. Ainda é comum que os conteúdos sejam apresentados de forma fragmentada e isolada de seus contextos de produção social, com o objetivo de levar ao aluno um conhecimento já pronto e organizado, (sub)entendendo-se com isso facilitar a aprendizagem. Centrados em metodologias muito formais e distantes da realidade vivenciada pelos alunos, porém, os saberes tornam-se isolados dos processos de construção dos conceitos envolvendo problemas e as questões que os originaram (KATO et al., 2011). Nesse sentido, a contextualização no ensino de Ciências da Natureza torna-se um tema relevante a ser investigado ao direcionarmos o olhar para os contextos que são próximos e significativos aos alunos, promovendo a inter-relação entre o que se aprende na escola e o que se vivencia.

Para Lutfi (1992), a contextualização é mais do que a mera ligação entre conceitos cotidianos e científicos, deve promover a compreensão de problemas sociais e contribuir para que o aluno consiga intervir no meio em que vive. Desse modo, compreendemos a contextualização como um recurso potencializador para as mais diversas inter-re- 
lações entre os conhecimentos escolares e os cotidianos, promovendo a compreensão de problemas sociais e contribuindo para nossa intervenção no ambiente que nos cerca. Assim, levar em conta a contextualização nos processos de ensino e aprendizagem qualifica nossos entendimentos e amplia nossos olhares no estudo de determinada temática.

Nessa direção, o foco da presente investigação consistiu em identificar compreensões de professores do ensino de Ciências acerca da contextualização em publicações da área. Para tanto realizamos uma revisão bibliográfica nos anais publicados no Encontro Nacional de Pesquisa em Educação em Ciências (Enpec) de 2005 a 2015 contemplando um período de dez anos e um total de 6 eventos. Selecionamos os trabalhos que apresentam o termo contextualização no título e/ou nas palavras-chave. A escolha pelo evento é justificada por contemplar discussões de pesquisas recentes e, nas temáticas, tratar de temas de interesse da comunidade de educadores em Ciências.

Para o estudo destacamos, ainda, a importância da compreensão do que é apresentado acerca da contextualização nos documentos curriculares brasileiros. 0 estudo contribui para compreendermos o planejamento das atividades escolares ao considerarmos que é preciso haver coerência entre o que a legislação propõe e o que a escola busca desenvolver, em especial no contexto atual de proposição da Base Nacional Comum Curricular (BNCC).

\section{CONTEXTUALIZAÇÃO: Um Olhar Para os Documentos Curriculares}

No Brasil, nos últimos anos, foram propostas diversas reformas educacionais decorrentes da Lei de Diretrizes e Bases da Educação Nacional (LDB) de 1996, entre as quais destacamos a busca por uma nova identidade ao Ensino Médio. Na LDB consta que, ao final desse nível de ensino, o aluno deve estar em condições de partir para a realização de seus projetos pessoais e coletivos (BRASIL, 1996). A lei propõe uma nova forma de compreender o currículo escolar ao considerá-lo determinante para a promoção de valores vinculados ao interesse social dos cidadãos. Em decorrência disso, foram estabelecidas as Diretrizes Curriculares Nacionais (DCNs), que visam a fornecer orientações para a instituição das mudanças.

No contexto atual da Educação Básica brasileira temos vivenciado momentos de tensão e conflitos permanentes que decorrem das discussões oriundas da proposta de efetivação da BNCC e das novas diretrizes curriculares para a formação de professores, aprovadas pelo Conselho Nacional de Educação em 2015. Ambos os documentos devem ser levados em consideração nos processos de formação de professores, pois convergem quanto à intenção de promover um ensino mais contextualizado na Educação Básica.

No que se refere à BNCC, identificamos que a contextualização é apresentada como tarefa fundamental para atribuição de significados condizentes a determinados contextos (BRASIL, 2016). Ou seja, um meio de compreendermos as situações reais por nós vivenciadas, de modo que os conceitos discutidos em sala possam ser significados e compreendidos em situações do contexto escolar e cotidiano como um todo. 
$\mathrm{Na}$ condição de cidadãos, estamos imersos em um universo de relações sociais pelas quais nos constituímos. Sendo assim, as vivências e as relações estabelecidas, tanto com o ambiente físico como com o social, devem servir como base para que os conteúdos escolares sejam significados.

Dessa forma, considerando que o contexto é o que constitui os sujeitos e, portanto, mais explorável para dar significado, o objetivo da contextualização no ensino, de acordo com os documentos analisados, não é simplesmente promover uma ligação entre o que é ensinado na sala de aula e a vida cotidiana do aluno de modo a facilitar a aprendizagem, mas sim propor situações problemáticas, de modo a oportunizar um processo de (re)construção de significados, direcionando a um conhecimento escolar mais significativo.

As DCNs para a Educação Básica (BRASIL, 2010) trazem o currículo como um conjunto de valores e práticas que proporcionam a produção, a socialização de significados no espaço social e contribuem intensamente na construção de identidades socioculturais dos educandos. Segundo o texto, na organização da proposta curricular

[...] deve-se assegurar o entendimento de currículo como experiências escolares que se desdobram em torno do conhecimento, permeadas pelas relações sociais, articulando vivências e saberes dos estudantes com os conhecimentos historicamente acumulados e contribuindo para construir as identidades dos educandos (BRASIL, 2010, p. 4).

O percurso formativo é compreendido como sendo aberto e contextualizado e que deve ser construído de acordo com os interesses e necessidades dos alunos, bem como em função das peculiaridades do meio. Assim, podemos enfatizar que o tratamento contextualizado do conhecimento é um dos recursos de que a escola dispõe para retirar o aluno da condição apenas de espectador e estimulá-lo a participar, fazer, recriar por meio da reconstrução de seus contextos, uma aprendizagem mais expressiva , não significando banalizar o conhecimento ou o conteúdo das disciplinas, mas criar condições para que os alunos, a partir de seus conhecimentos, nas múltiplas relações estabelecidas, passem a compreender também o conhecimento científico.

Partindo da análise dos documentos, identificamos a contextualização como um meio que proporciona aos alunos condições para que se apropriem e signifiquem os conteúdos de Ciências que constituem o conhecimento escolar. Com isso, reforçamos a necessidade de superar, nas práticas de ensino, a simples repetição de definições que se caracteriza como um processo vazio de significado ao aluno. Buscando ampliar a compreensão acerca da contextualização no âmbito do ensino de Ciências realizamos uma análise da abordagem dessa temática nas publicações do Enpec. Segue-se a descrição da metodologia adotada e o diálogo estabelecido com os resultados construídos e o referencial teórico.

\section{METODOLOGIA}

Tendo como objetivo qualificar a compreensão quanto aos modos e concepções de contextualização no ensino de Ciências, realizamos, além da revisão acerca da contextualização nos documentos oficiais (BRASIL, 2000, 2010), uma revisão bibliográfica 
nos artigos publicados no Encontro Nacional de Pesquisa em Educação em Ciências (Enpec) dos últimos dez anos, totalizando seis eventos (o evento acontece bienalmente). Para a seleção dos trabalhos usamos os descritores "contextualização", "recontextualização" e "contextualizado(a)". Dessa forma, foram separados inicialmente 57 artigos. Num dos artigos a palavra "contextualização" estava apenas mencionada nas palavras-chave e foi discutida no decorrer do texto; com isso, optamos por não analisá-lo, ficando, assim, uma amostra de 56 artigos.

Para o primeiro ciclo da análise usamos como aporte a Análise Textual Discursiva (ATD), a qual, de acordo com Moraes (2003),

[...] pode ser compreendida como um processo auto-organizado de construção de compreensão em que novos entendimentos emergem de uma sequência recursiva de três componentes: desconstrução dos textos do corpus, a unitarização; estabelecimento de relações entre os elementos unitários, a categorização; o captar do novo emergente em que a nova compreensão é comunicada e validada (p. 192).

Analisamos os enunciados referentes à temática estudada e para isso nosso olhar foi guiado por duas perguntas iniciais: Qual a compreensão dos autores/pesquisadores sobre contextualização? Como a contextualização está sendo proposta no Ensino de Ciências pelos autores? O movimento inicial de questionamento contemplou o objetivo geral da pesquisa e iniciou-nos no processo de impregnação com os textos.

Na sequência passamos a focalizar, no segundo momento do ciclo de análise, a categorização das unidades. As categorias foram sendo construídas ao organizarmos os conjuntos de elementos semelhantes, que na via da ATD se caracterizam em um processo de comparação constante entre as unidades definidas no processo inicial de análise, levando a agrupamentos de elementos semelhantes, consistindo os conjuntos de elementos de significação próximos nas categorias (MORAES, 2003, p. 197).

O processo de análise resultou nas seguintes categorias: a) contextualização como ensino significativo; b) contextualização como inter-relação do conhecimento científico $e$ do conhecimento cotidiano e c) contextualização como superação do modelo de ensino transmissivo. As categorias não são excludentes no processo de ensino, e por sua vez alguns artigos explicitavam mais uma ou outra categoria, com a primeira apresentando-se de forma mais ampla englobando aspectos característicos das demais. Em todas foi possível indiciar novas perspectivas de perceber o conteúdo, tanto do aluno como do professor em sala de aula, o que implica novas formas de compreender o ensino, daí referendarmos a importância da presente investigação e da compreensão do termo contextualização no Ensino de Ciências no contexto atual.

Como terceiro ciclo da análise, trabalhamos com as categorias a fim de expressar nossas compreensões com relação ao fenômeno investigado. O objetivo da análise consistiu em trazer uma discussão sobre os resultados encontrados, enfatizando equívocos, indícios, desafios, dificuldades e possibilidades que permeiam os processos de contextualização na sala de aula e no Ensino de Ciências como um todo. A seguir apresentamos um diálogo com os resultados oriundos de nossas compreensões num embasamento teórico com Vigotski $(2000,2007)$, Santos $(2004)$, Lopes $(1997,2007)$ e outros referenciais da área. 


\section{CONTEXTUALIZAÇÃO: Diálogos no Ensino de Ciências}

O processo de análise realizado permitiu identificarmos ideias compartilhadas, também, por alguns autores (LOPES, 1997, 2007; SANTOS, 2004; VIGOTSKI, 2000, 2007) ao dialogarem acerca da contextualização no ensino, os quais auxiliaram nossas compreensões acerca das categorias decorrentes da análise. Para a discussão os artigos são denominados de $E_{1}, E_{2} \ldots E_{56}$. Entre os 56 artigos analisados, em 9 não foi possível identificar elementos que pudessem contribuir ao processo de análise, tendo em vista que apresentavam no título e/ou palavras-chave os descritores de busca, no entanto na escrita do artigo a contextualização não era o foco de discussão, e desse modo não contemplaram os questionamentos iniciais, os quais direcionaram nossos entendimentos a respeito da temática.

O Gráfico 1, que segue, indica a incidência das categorias entre todos os artigos analisados. Destacamos que alguns artigos acenam para mais de uma categoria.

Gráfico 1 - Incidência das categorias que perpassaram os artigos analisados em seis edições do Enpec

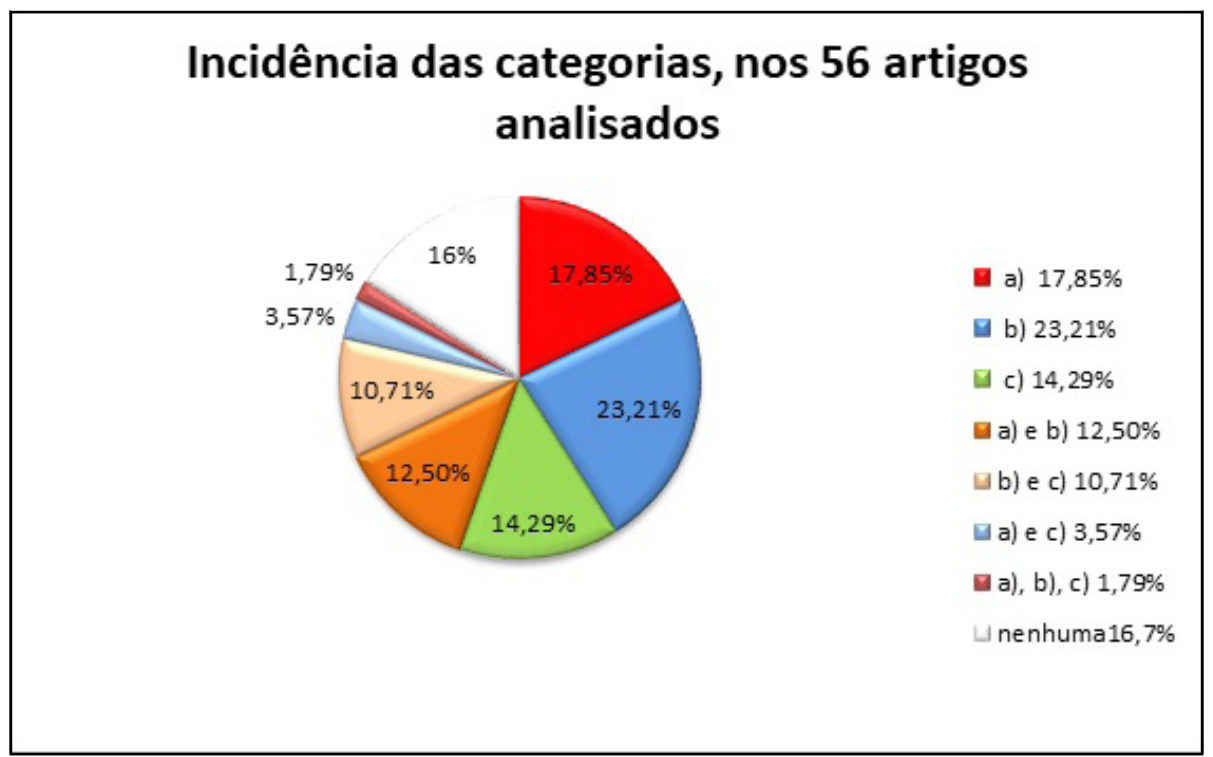

a) contextualização como ensino significativo; b) contextualização como inter-relação do conhecimento científico e do conhecimento cotidiano e c) contextualização como superação do modelo de ensino transmissivo.

Fonte: Arquivo próprio.

Tendo em vista qualificar a compreensão quanto ao uso do termo, destacamos que foi possível identificar somente em cinco artigos uma definição mais explícita sobre contextualização, por exemplo, no artigo $\mathrm{E}_{48}$, em que o autor afirma que a contextualização "inter-relaciona conhecimentos diferentes contribuindo para a estruturação de novos significados. Contextualizar, portanto, é construir significados" (SANTOS, 2010, p. 3).

Ainda, em $\mathrm{E}_{4} \mathrm{O}$ autor defende a contextualização como forma de tornar o conteúdo mais interessante para o aluno. De acordo com o autor, "[...] contextualizar o ensino é aproximar o conteúdo formal (científico) do conhecimento trazido pelo aluno (não formal) e dessa forma fazer com que o conteúdo seja interessante para ele, à medida que este se encontra dentro de sua realidade de vida (cotidiano)" (KATO; KAWASAKI, 
2007, p. 3). Já em $E_{5}$ identificamos uma compreensão mais significativa do processo de contextualização: "contextualizar o ensino não implica em facilitar o processo de ensino e aprendizagem, mas possibilitar que as inter-relações necessárias entre contextos vivenciais e os conceitos científicos ocorram para a construção de um conhecimento escolar significativo" (ZANON et al., 2007, p. 7).

Pelos excertos demarcamos uma maior aproximação em $E_{48}$ e $E_{5}$, uma vez que os autores consideram a contextualização como um processo de construção de significados. Nesse sentido, $E_{5}$ vai além, ao direcionar a contextualização não como um modo de facilitar a aprendizagem, mas de relacionar o senso comum aos conhecimentos científicos, de modo a construir um conhecimento escolar mais significativo. Isso corrobora as ideias de Mortimer (1998), ao apontar para a necessidade de diálogo entre todos os tipos de conhecimentos. Com isso, segundo o autor, a concepção de ciência como um conjunto de verdades imutáveis e da ciência como algo estático é decorrente da

[...] falta de diálogo [...] entre a linguagem científica e a linguagem cotidiana, entre a realidade criada pela ciência e a realidade da vida cotidiana, entre a teoria científica e a prática dos fenômenos, entre os princípios científicos e os contextos sociais e tecnológicos em que eles se materializam (1998, p. 115).

Dessa forma, podemos acenar que o ensino a ser regido por normas e formas estipuladas por um currículo determinante na escola, em que coexistem saberes, tempos, espaços e contextos diferenciados, não contribui para a formação do sujeito. $O$ ensino para se tornar compreensível precisa privilegiar as concepções que os alunos já trazem dos seus contextos, valorizando formas de problematizar essa realidade de forma a estimular um aprendizado significativo, que favoreça sua compreensão de mundo. De acordo com Lopes (1997, p. 51), "[...] é com essa pluralidade de saberes e de diferentes formas de ver e interpretar o mundo que precisamos ensinar nossos alunos e nossas alunas a conviver".

Desse modo, no que se refere a definições mais explícitas para a contextualização no ensino, não foram indiciadas nos demais artigos. A seguir uma discussão, com base nas categorias que emergiram do processo de análise.

\section{Contextualização Como Ensino Significativo}

A categoria contempla compreensões acerca da contextualização como princípio norteador do currículo escolar, considerando que a educação abrange processos formativos, que se desenvolvem em diversos espaços: na vida familiar, nas relações de convivência entre os indivíduos, nas organizações da sociedade, nas instituições de ensino, entre outros, necessitando serem problematizadas e significadas de maneira a contribuírem para a formação do sujeito. Acreditamos que o professor, ao atuar numa perspectiva sociocultural, consegue desafiar e problematizar o conhecimento do senso comum no sentido de torná-lo mais significativo ao aluno.

No processo de pesquisa identificamos a concepção de contextualização como viés de um ensino significativo presente em 20 artigos, correspondendo a $(35,71 \%)$, conforme o Gráfico 2. 
Gráfico 2 - Incidência da presença da categoria a

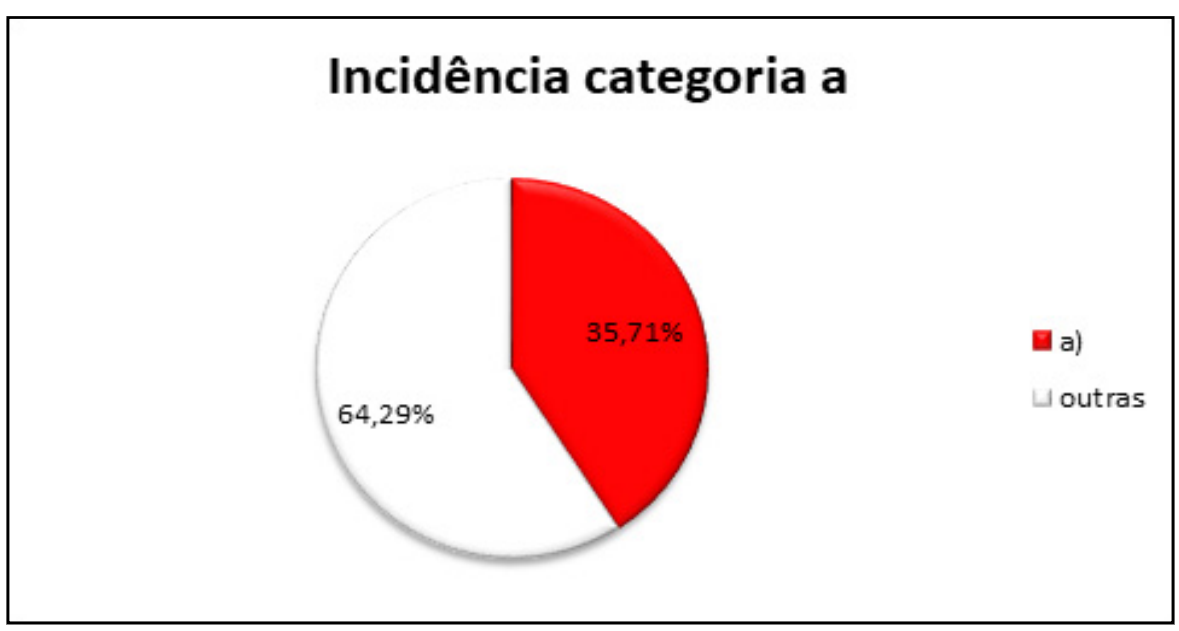

a) Contextualização como viés de um ensino significativo.

Fonte: Arquivo próprio.

Seguem-se alguns excertos pincelados dos artigos e que remetem à categoria:

[...] além de planejar e articular as estratégias e os conteúdos precisamos interpretar os temas até uma práxis social, a fim de significá-los nos diferentes contextos de alunos e alunas, em sala de aula e fora dela (SEVERO; DIAS, 2011, p. 2).

[...] aulas descontextualizadas e que reforçam a necessidade de memorização de nomes e termos técnicos, desprovidos de sentido aos alunos não dão conta de promover uma aprendizagem significativa (SANTOS, 2010, p. 7).

Vigotski (2007) afirma que a aprendizagem só é significativa quando os alunos conseguem internalizar o novo conceito de forma a operar com ele em diferentes situações, que passe a fazer parte de sua visão de mundo, ou seja, relacionar os conceitos trabalhados em sala de aula com situações vividas em seus contextos.

Com base no referido autor, vemos a importância da compreensão do contexto histórico-social do aluno no processo de ensino. $O$ sujeito é observado como um agente interativo no processo de criação de seu ambiente e não apenas como um produto de seu meio, destacando a importância do estabelecimento de relações com o conhecimento prévio (histórico-social) dos alunos, com ênfase na constituição do sujeito. $E_{12}$ aproxima-se dessa concepção ao explicitar que

[...] a contextualização consiste em atribuir sentido e significado ao que é vivido e uma oportunidade para o professor tornar o aluno capaz de assumir posições diante de situações e problemas reais e de ampliar seu nível de conhecimento científico e tecnológico, de modo a utilizá-lo como instrumento para compreender e modificar o seu contexto social. Os conteúdos deixam, assim, de serem fins em si mesmos (ou para aprovação em um vestibular) para se tornarem meios para a interação com o mundo, fornecendo ao aluno instrumentos para construir uma visão articulada, organizada e crítica da realidade (HARTMANN; ZIMMERMANN, 2010 p. 5).

Desse modo, ao propor aos alunos instrumentos para a construção de uma visão crítica e de uma aprendizagem significativa, os processos de mediação tornam-se essenciais, observando-se que as atividades mediadas é que irão orientar os seus compor- 
tamentos, acarretando em mudanças no seu funcionamento cognitivo. Assim, ao professor cabe sempre o desafio de encontrar estratégias de provocar tensões para com as experiências e concepções dos alunos no contexto da sala de aula para a construção e a internalização dos conceitos científicos, com o intuito de torná-los mais participativos e críticos para com o meio social.

Vigotski (2000) conceitua o processo de internalização como a reconstrução interna de uma operação externa. Nesse sentido, a linguagem oportuniza a aprendizagem, desenvolve meios para o professor fomentar as discussões, problematizando o conhecimento que os alunos trazem para a sala de aula (adquirido no contexto de suas vivências) no sentido de (re)construir conhecimentos cada vez mais complexos.

O autor (2000), ao reforçar o estabelecimento das relações sociais, remete à contribuição da aprendizagem por meio da mediação de instrumentos e signos, a qual contribui para a formação social do homem. Enquanto o signo constitui-se num meio de atividade interna voltada ao controle do próprio indivíduo, o instrumento é orientado externamente para o controle e domínio da natureza.

Nesse sentido, o meio social mostra-se fundamental para a compreensão do sujeito, com sua constituição dando-se na interação social, e a linguagem, em sua dimensão constitutiva, tem um papel fundamental, pois conhecemos a partir da linguagem e também por meio dela manifestamos o que conhecemos. Dessa forma, a linguagem pode fornecer meios para o professor fomentar discussões em sala de aula, sendo fundamental que o professor perceba a linguagem como propulsora e potencializadora do ensino e da aprendizagem.

O movimento instiga a capacidade de criação e participação crítica, requerendo do aluno um posicionamento diante das transformações de seu meio e não simplesmente aceitar o que está posto e repetir o que lhe foi apresentado.

\section{Contextualização Como um Movimento de Inter-Relação do Conhecimento Científico e do Conhecimento Cotidiano}

A categoria contempla o que Santos (2004) discute ao argumentar que vivemos um momento de transição entre o paradigma da ciência moderna e um novo paradigma emergente: o da ciência pós-moderna. O período de mudança busca a superação da fragmentação das Ciências e as suas implicações para a humanidade, daí a necessidade do diálogo entre saberes.

O autor (2004) propõe um novo modelo de ciência a partir da inter-relação entre Ciências Naturais e Ciências Sociais, fraturando o modelo totalitário das Ciências Naturais, via única e possível para se atingir uma "verdade universal". Para ele todo "conhecimento científico é socialmente construído, o seu rigor tem limites ultrapassáveis e a sua objetividade não implica em sua neutralidade" (SANTOS, 2004, p. 9). Nesse sentido, com base no autor, todo conhecimento científico deve dialogar com o senso comum, mas com a pretensão tanto de iluminá-lo quanto de ser iluminado por ele. Passagens que se aproximam dessa concepção e que compartilham da contextualização como um 
movimento de inter-relação do conhecimento científico e do conhecimento cotidiano foram encontradas em 27 artigos (48,21\%), conforme o Gráfico 3. Podemos destacar que essa categoria foi a que mais esteve presente nos artigos analisados.

$U m$ excerto que representa essa categoria foi pincelado de $E_{5}$ ao trazer que "contextualizar o ensino não implica em facilitar o processo de ensino e aprendizagem, mas, possibilitar que as inter-relações necessárias entre os contextos vivenciais e os contextos científicos ocorram para a construção de um conhecimento escolar significativo" (ZANON et al., 2007, p. 7).

Gráfico 3 - Incidência da presença da categoria b

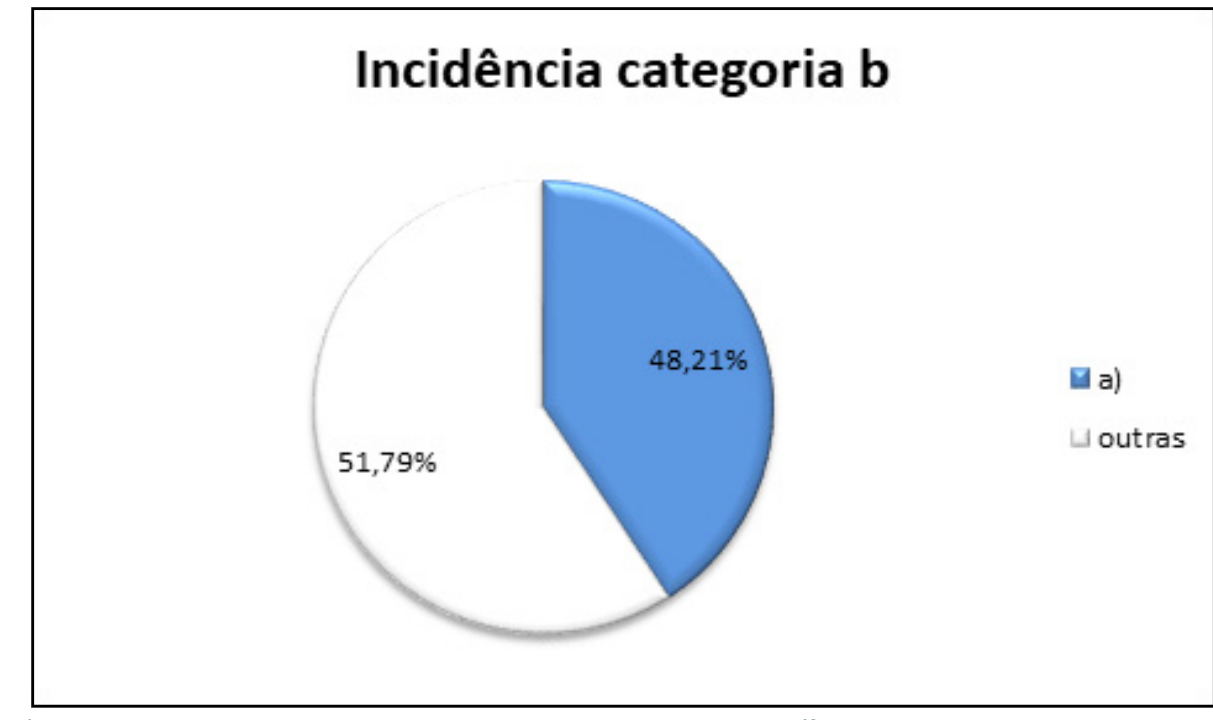

b) contextualização como inter-relação do conhecimento científico e do conhecimento cotidiano.

Fonte: Arquivo próprio.

Nessa direção, Lopes (1997) nos auxilia quanto à compreensão das distinções entre conhecimento científico e escolar. No entendimento da autora,

à comunidade científica cabe a construção do novo conhecimento, a busca pelo desconhecido, a retificação do já sabido. A comunidade escolar, ao contrário, trabalha com a aceitação prévia do conhecimento produzido em outras instâncias e tem por objetivo torná-lo ensinável, acessível ao nível de compreensão do estudante (LOPES, 1997, p. 52).

Tendo em vista que conceitos científicos se fazem cada vez mais presentes em nosso entorno (noticiários, revistas, rótulos de embalagens) e que a razão acaba por se acomodar ao que já se conhece, procurando manter uma continuidade do conhecimento, necessitamos recorrer ao papel da escola que tem a sala de aula como um espaço de sistematização, organização, discussão, produção e significação de conceitos, entre outras características, possibilitando pôr em confronto conhecimentos prévios, para que de fato os conceitos científicos possam ser significados pelos alunos.

Assim, faz-se necessária a problematização dos saberes que os alunos já possuem sobre os conteúdos, suas assimetrias ao interagirem com as vivências e contextos socioculturais, que incidem em interações capazes de proporcionar processos de (re)construção de conhecimentos, em que, segundo Lopes (2007, p. 39), " o conhecimento, como 
produto do processo de conhecer, reflete o real e tanto mais objetivo e científico será quanto maior for o grau de reflexão alcançado". Esse processo, no entanto, não implica o abandono das teorias anteriormente construídas. Trata-se, sim, de reordenar, de ir além de seus pressupostos, por introduzir uma nova racionalidade.

Vigotski (2000) chama a atenção para a importância do elo entre as duas formas de formação conceitual e também de pensamento: a cotidiana e a científica. Ambas ocorrem em sentidos opostos, mas não seguem trajetórias paralelas. Uma não anula a outra, pelo contrário, podem se cruzar várias vezes, fundir-se, separar-se, ou, ainda, andar lado a lado. O importante, como salienta o autor, é considerar que um processo de formação conceitual enriquece o outro.

$\mathrm{Em} \mathrm{E}_{9}$ tal posicionamento pode ser identificado:

[...] o conteúdo apresentado deve estar inserido no cotidiano do aluno, contextualizando o conhecimento científico com a realidade social. No entanto para que isso ocorra, não se pode confundir a contextualização com a exemplificação. No caso, a exemplificação é uma breve correlação entre o conteúdo trabalhado em sala de aula e o cotidiano do aluno. Já a contextualização é o processo inverso: a partir do cotidiano do aluno chega-se à exploração dos conceitos químicos pertinentes a esse (RADUCK; RADUCK, 2010, p. 2).

No fragmento o autor menciona que a simples exemplificação dos conteúdos não contribui para com a aprendizagem, isso é ressaltado em Lopes (2007) ao enfatizar, com base em Bachelard, a questão dos obstáculos epistemológicos, que se constituem ao se introduzir um número excessivo de analogias, metáforas no sentido de tornar familiar a aprendizagem de conhecimentos abstratos.

[...] a razão acomodada ao que já se conhece, procurando manter a continuidade do conhecimento, opõe-se à retificação dos erros ao introduzir, por exemplo, um número excessivo de analogias, metáforas e imagens no próprio ato de conhecer, como o fim de tornar familiar todo o ato de conhecimento abstrato, constituindo, assim, obstáculos epistemológicos (LOPES, 2007, p. 45).

A autora adverte, também, que a (re)construção do conhecimento escolar se dá por constantes rupturas para com a linearidade dos conhecimentos construídos pelos alunos, em que o conhecimento científico vai se constituindo mediante rupturas com o conhecimento cotidiano, tornando desse modo a aprendizagem significativa. Cabe ressaltar, todavia, que há a necessidade de participação ativa do professor e também do aluno em sala de aula, em que diálogos e aprendizados devem ocorrer simultaneamente, no sentido de promover a (re)construção do conhecimento escolar. Nesse sentido,

[...] cabe ao professor o papel de mediar o acesso às linguagens e significados produzidos, antes, no âmbito científico, cujas conceitualizações, dialogicamente articuladas com conhecimentos dos estudantes, precisam "romper com o senso comum” (SANTOS, 2003), romper com “a impressão primeira” (BACHELARD, 1996), permitindo que os estudantes reinterpretem, à luz da ciência, as situações reais do cotidiano (SANGIOGO; ZANON, 2014, p. 159). 
Desse modo é imprescindível que os professores da área das Ciências da Natureza repensem os modos de ensino que contemplem apenas metodologias que priorizem a memorização, tendo em vista que os conteúdos ao não serem significados, são esquecidos. O professor precisa privilegiar metodologias que problematizem as vivências dos alunos de modo a possibilitar a apropriação da linguagem científica, de forma a criar sentido aos significados conceituais. Segue-se uma discussão referente à terceira categoria de análise.

\section{Contextualização Como um Movimento Metodológico de Superação do Modelo de Ensino Transmissivo}

A categoria contempla aspectos apontados por Vigotski (2007), ao compreender o sujeito como agente ativo (interativo) no processo de criação do ambiente e não apenas como um produto do meio. Visualizamos essa concepção no processo de análise em 17 artigos (30,36\%), conforme indica o Gráfico 4.

Gráfico 4 - Incidência da presença da categoria c

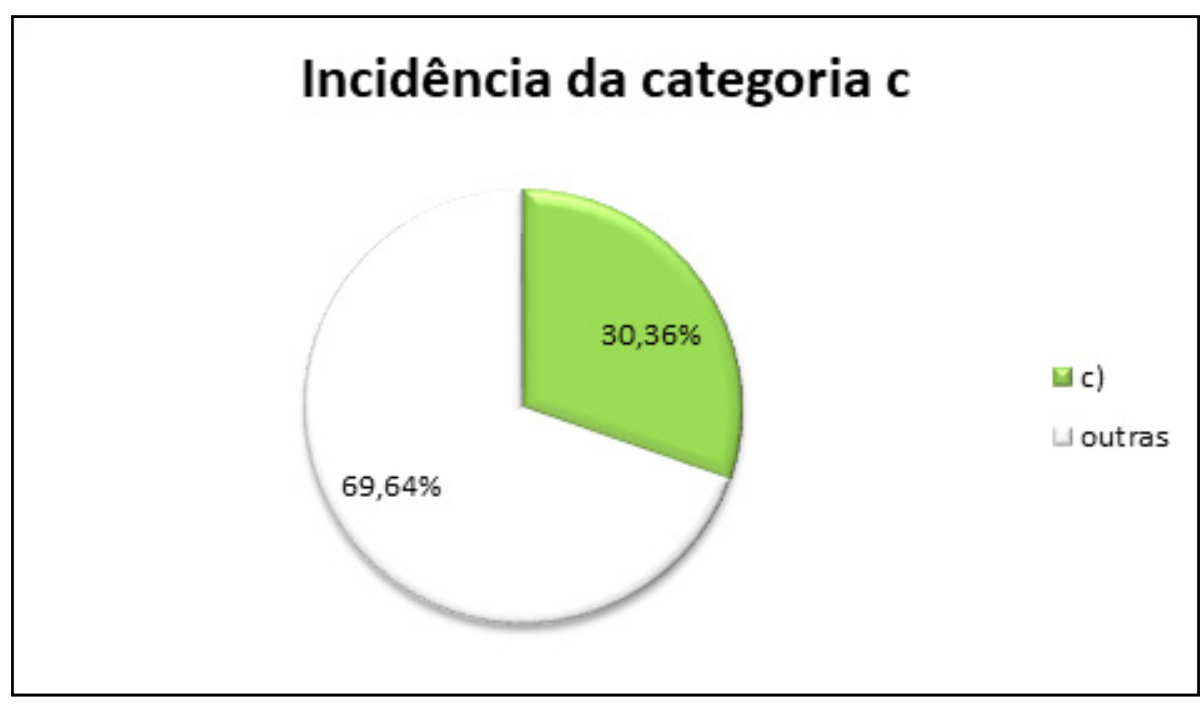

c) contextualização como superação do modelo de ensino transmissivo.

Fonte: Arquivo próprio.

Os excertos analisados mostram que os autores abordam a contextualização como um processo metodológico de superação do modelo de ensino transmissivo (tradicional), apontando diferentes interações. Seguem-se alguns excertos que remetem para a categoria em questão:

[...] é nesse nível de consciência que se pretende chegar ao se propor o ensino de Química com encaminhamentos pedagógicos norteados pela Alfabetização Científico-Tecnológica com caráter social. Ou seja, a busca da verdadeira democracia, com a liberdade para o questionamento e o diálogo, viabilizando por uma educação dialógica, ativa, interessada e participante da responsabilidade social e política, interpretando os problemas com a necessária profundidade (AIRES; LAMBACH, 2010, p. 5). 
[...] há, portanto, a necessidade de se rever o modelo de ensino de Botânica atual, buscando outro que priorize a contextualização e a aprendizagem significativa, aliado à formação de cidadãos críticos, consciente e atuantes na realidade que os cerca (SANTOS, 2010, p. 1).

Foi possível identificar a busca pelo diálogo, pelo questionamento em sala de aula, de modo a superar o ensino transmissivo e possibilitar a sua efetiva participação tanto em sala de aula como na sociedade. Maldaner (2003) ressalta que

[...] sempre tivemos a preocupação de sermos mais eficientes em sala de aula para que os alunos atingissem níveis de compreensão da ciência compatíveis com o desenvolvimento científico praticado pela comunidade científica, sem termos tido a preocupação de como essa ciência poderia transformar a vida prática dessas pessoas, tornando-as mais competentes e participativas em seu meio social (p. 152).

Nesse sentido, é necessário que os professores desenvolvam aulas que se projetem a ultrapassar os muros da escola, aulas que abordem questões relacionadas à diversidade cultural, democracia, melhoria da qualidade de vida, que permitam com que o próprio aluno estabeleça as relações necessárias para aprender e compreender o contexto social como um todo. Consideramos que as ideias e concepções construídas ou reelaboradas pelos sujeitos refletem as vivências nas quais os indivíduos estão inseridos, daí a importância do seu compartilhamento em sala de aula.

Outrossim, importante ressaltar que o processo de contextualizar deve ser vivenciado tanto pelo professor como pelo aluno. $\mathrm{O}$ autor em $\mathrm{E}_{7}$ afirma que

[...] o que se pretende é que os professores de Química da Educação Básica, utilizem tais recursos pedagógicos de forma a mediatizar o conhecimento. Assim, considerando o papel mediatizador do professor, estruturado na perspectiva da educação problematizadora - libertadora, pode ser possível utilizar os Objetos de Aprendizagem, como recurso para a problematização de situações existenciais dos educandos e, por conseguinte, ser empregado como contextualizador no ensino de Química (AIRES; LAMBACH, 2010, p. 6).

Importante enfatizar a partir do excerto que o autor faz referência à contextualização somente como trabalho do professor, contudo quais as garantias que temos com relação à aprendizagem dos alunos quando a contextualização é realizada somente pelo professor? Com isso reforçamos a importância em promovermos a compreensão de contextualização como processo também do pensamento do aluno, o que implica uma visão de aprendizagem significativa.

Nessa direção, quando professor e aluno conseguem realizar o processo de contextualização, pode-se visualizar aspectos do aprendizado. Para tanto, o professor precisa proporcionar metodologias diversificadas e que privilegiem/oportunizem um ensino contextualizado, e aos alunos é necessário o comprometimento e a participação inerente ao processo.

\section{CONSIDERAÇÕES FINAIS}

No processo de análise três compreensões acerca da contextualização foram mais recorrentes e constituíram as categorias de análise. Uma contemplando uma compreensão mais ampliada de contextualização, apresentando-a como uma metodologia usada 
em sala de aula de modo a conceber um ensino mais significativo comprometido com a aprendizagem efetiva do aluno. Outra, como um movimento de inter-relação entre o conhecimento científico e o cotidiano, em que o conhecimento escolar a ser construído leva em conta a sociedade e seus contextos. E a última como um movimento metodológico de superação do modelo de ensino tradicional, entendido como transmissivo, que enfatiza o diálogo e a interação dos alunos no processo de ensino-aprendizagem, levando o aluno a se posicionar criticamente diante do conhecimento.

De um modo geral, a primeira categoria tende a contemplar as demais, no sentido de que todas enfatizam a contextualização como meio de significar os conteúdos, possibilitando ao aluno criticidade e informação para com o meio em que vive. Isso é possível evidenciar ao ser ressaltada em todas as categorias a importância da mediação do professor, da problematização dos conteúdos, dos diálogos entre professor e aluno, viabilizando ao aluno operar com os conceitos científicos em diferentes situações.

Ao empreendermos estudos nos documentos que regem o currículo escolar, identificamos que a contextualização é tema recorrente. Inicialmente proposto como princípio pedagógico em decorrência da LDB de 1996 e, mesmo após quase 20 anos, mantém-se como aspecto determinante dos processos metodológicos na educação básica. Nossa preocupação com relação à compreensão conceitual do termo foi determinante na realização do presente estudo, pois entendemos que a forma como está expresso nos documentos oficiais, de forma especial nos PCNEM (2000) e DCN (2010), é muito incipiente, o que não contribui para o entendimento mais significativo acerca do processo nos espaços de ensino e aprendizagem.

Nesse sentido, considerando a revisão nos artigos publicados no Enpec, podemos enfatizar que as concepções de contextualização diferem quanto ao sentido expresso nas escritas. Assim, compreendemos a necessidade de investir em mais estudos acerca das concepções que perpassam o conceito de contextualização nos espaços de ensino a fim de contribuir com a realização de processos que efetivamente contemplem o contexto do aluno no sentido de auxiliar a ressignificação dos conceitos da ciência em espaços distintos da sala de aula.

\section{REFERÊNCIAS}

AIRES, J. A.; LAMBACH, M. Contextualização do ensino de química pela problematização e alfabetização científica e tecnológica: uma experiência na formação continuada de professores. In: ENCONTRO NACIONAL DE PESQUISA EM EDUCAÇÃO EM CIÊNCIAS - ENPEC, 7., 2010, Florianópolis. Anais [...]. Florianópolis, SC, v. 10, n. 1, p. 1-8, nov. 2010. Disponível em: file://C:/Users/Notebook/Downloads/2182-5690-1-PB. pdf. Acesso em: 24 maio 2016.

BRASIL. Parâmetros Curriculares Nacionais para o Ensino Médio. Conselho Nacional de Educação, Secretaria de Educação Básica. Brasília, 2000. Disponível em: http://portal.mec.gov.br/seb/arquivos/pdf/blegais.pdf. Acesso em: 8 jul. 2017.

BRASIL. Diretrizes e Bases da Educação Nacional. Conselho Nacional de Educação, Secretaria de Educação Básica. Lei no 9394 de 20 de dezembro de 1996. Brasília, 1996. Disponível em: http://portal.mec.gov.br/ seesp/arquivos/pdf/lei9394_Idbn1.pdf. Acesso em: 8 jul. 2017.

BRASIL. Diretrizes Curriculares Nacionais Gerais para a Educação Básica. Conselho Nacional de Educação, Secretaria de Educação Básica. Resolução no 4, de 13 de julho de 2010. Brasília, 2010. Disponível em: http://portal.mec.gov.br/dmdocuments/rceb004_10.pdf. Acesso em: 8 jul. 2017.

BRASIL. Ministério da Educação. Secretaria da Educação Básica. Texto preliminar da BNCC. 2016. Disponível em: http://basenacionalcomum.mec.gov.br. Acesso em: 8 de jul. 2017. 
HARTMANN, A. M.; ZIMMERMANN, E. Feira de ciências: a interdisciplinaridade e a contextualização em produções de estudantes de ensino médio. In: ENCONTRO NACIONAL DE PESQUISA EM EDUCAÇÃO EM CIÊNCIAS - ENPEC, 7., 2010, Florianópolis, SC. Anais [...]. v. 10, n. 1, p. 1-8, nov. 2010. Disponível em: http://posgrad.fae.ufmg.br/posgrad/viienpec/pdfs/178.pdf. Acesso em: 24 maio 2016.

KATO, D. S et al. As concepções de contextualização do ensino em documentos curriculares oficiais e de professores de ciências. Revista Ciência e Educação, v. 17, n. 1, p. 35-50, 2011.

KATO, D. S. KAWASAKI, C. S. O significado pedagógico da contextualização para o ensino de ciências: análise dos documentos curriculares oficiais e de professores. In: ENCONTRO NACIONAL DE PESQUISA EM EDUCAÇÃO EM CIÊNCIAS - ENPEC, 6., 2007, Florianópolis. Anais [...]. Florianópolis, SC, v. 9, n. 9, p. 1-8, dez. 2007. Disponível em: http://www.nutes.ufrj.br/abrapec/vienpec/CR2/p782.pdf. Acesso em: 25 out. 2016.

LOPES, A. R.C. Conhecimento escolar: inter-relações com conhecimentos científicos e cotidianos. In: Contexto e Educação, Ijuí: Editora Unijuí, n. 45, p. 40-59, jan./mar. 1997.

LOPES, A. R. C. Currículo e epistemologia. Ijuí: Editora Unijuí, 2007. 228p.

LUTFI, M. Os ferrados e os cromados: produção social e apropriação privada do conhecimento químico. ljuí: Editora Unijuí, 1992.

MALDANER, O. A. A formação inicial e continuada de professores de química: professores/pesquisadores. 2. ed. Ijuí: Editora Unijuí, 2003. 424p.

MORAES, R. Uma tempestade de luz: a compreensão possibilitada pela análise textual discursiva. Revista Ciência e Educação, v. 9, n. 2, p. 191-211, 2003.

MORALES, R. S. Do biológico ao social: a linguagem em Vigotsky. Revista Cenários, Porto Alegre, n. 7, p. 79-88, $1^{\circ}$ semestre 2013. Disponível em: file:///C:/Users/USER/Downloads/579-1613-1-PB.pdf. Acesso em: 26 abr. 2016.

MORTIMER, E. F. Sobre chamas e cristais: a linguagem cotidiana, a linguagem científica e o ensino de ciências. In: CHASSOT, A. (org.). Ciência, ética e cultura na educação. São Leopoldo: Unisinos, 1998. 270p.

PAULETTI, F.; FENNER, R. S. F.; ROSA, M. P. A. A linguagem como recurso potencializador no Ensino de Química. Revista Perspectiva, Erechim, v. 37, n. 139, p. 7-17, set. 2011.

RADETZKE, F. S.; LEITE, F. A; WENZEL, J. S. Reflexões atinentes a contextualização no ensino de Ciências. In: SEPE/UFFS, 6. Anais... 2016.

RADUCK, F. B.; RADUCK, R. C. de S. R. A contextualização pelo trabalho: possibilidades de aprendizagem de conceitos científicos. In: ENCONTRO NACIONAL DE PESQUISA EM EDUCAÇÃO EM CIÊNCIAS - ENPEC, 7., 2010, Florianópolis. Anais [...]. Florianópolis, SC, v. 10, n. 1, p. 1-8, nov. 2010. Disponível em: file:///C:/ Users/Notebook/Downloads/2182-5690-1-PB.pdf. Acesso em: 24 maio 2016.

SANGIOGO, F. A.; ZANON. L. B. Conhecimento cotidiano, científico e escolar: especificidades e inter-relações enquanto produção de currículo e cultura. Cadernos de Educação, n. 47, p. 144-164, 2014.

SANTOS, B. de S. Um discurso sobre as ciências. 2. ed. São Paulo: Cortez, 2004. 92p.

SANTOS, M. L. et al. O ensino de botânica na formação inicial de professores em instituições de Ensino Superior Públicas no Estado de Goiás. In: ENCONTRO NACIONAL DE PESQUISA EM EDUCAÇÃO EM CIÊNCIAS - ENPEC, 10., 2010, Águas de Lindoia. Anais [...]. Águas de Lindoia, SP, v. 12, n.1, p. 1-8, nov. 2010. Disponível em: http://www.abrapecnet.org.br/enpec/x-enpec/anais2015/resumos/R0797-1.PDF. Acesso em: 24 maio 2016.

SEVERO, T. E. A.; DIAS, M. A. da S. Pressupostos da abordagem contextualizada: o ensino voltado para a educação ambiental e saúde. In: ENCONTRO NACIONAL DE PESQUISA EM EDUCAÇÃO EM CIÊNCIAS ENPEC, 8., 2011, Campinas. Anais [...]. Campinas, SP, v. 11, n. 1, p. 1-11, dez. 2011. Disponível em: http:// www.nutes.ufrj.br/abrapec/viiienpec/resumos/R1513-1.pdf. Acesso em: 24 maio 2016.

SILVA, E. L. Contextualização no ensino de química: ideias e proposições de um grupo de professores. Dissertação (Mestrado em Ensino de Ciências) - Instituto de Química da Faculdade de Educação da Universidade de São Paulo, São Paulo, 2007.

VIGOTSKI, L. S. A construção do pensamento e da linguagem. Trad. Paulo Bezerra. 1. ed. São Paulo: Martins Fontes, 2000.

VIGOTSKI, L. S. A formação social da mente: o desenvolvimento dos processos psicológicos superiores. 7. ed. São Paulo: Martins Fontes, 2007. 182p.

ZANON, L. B. et al. A contextualização como perspectiva na formação para o ensino em ciências naturais. In: ENCONTRO NACIONAL DE PESQUISA EM EDUCAÇÃO EM CIÊNCIAS - ENPEC, 6., 2007, Florianópolis. Anais... Florianópolis, SC, v. 9, n. 9, p. 1-8, dez. 2007. Disponível em: http://www.nutes.ufrj.br/abrapec/ vienpec/CR2/p591.pdf. Acesso em: 25 out. 2016. 